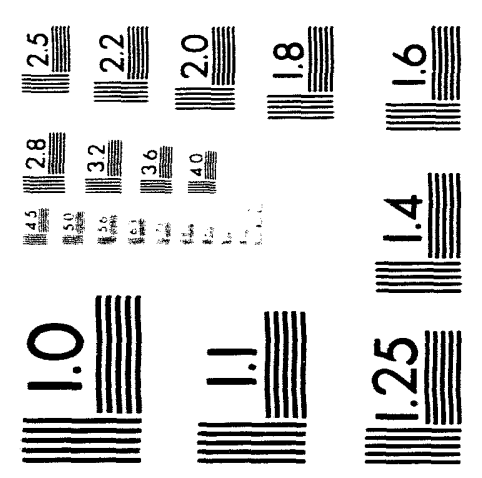



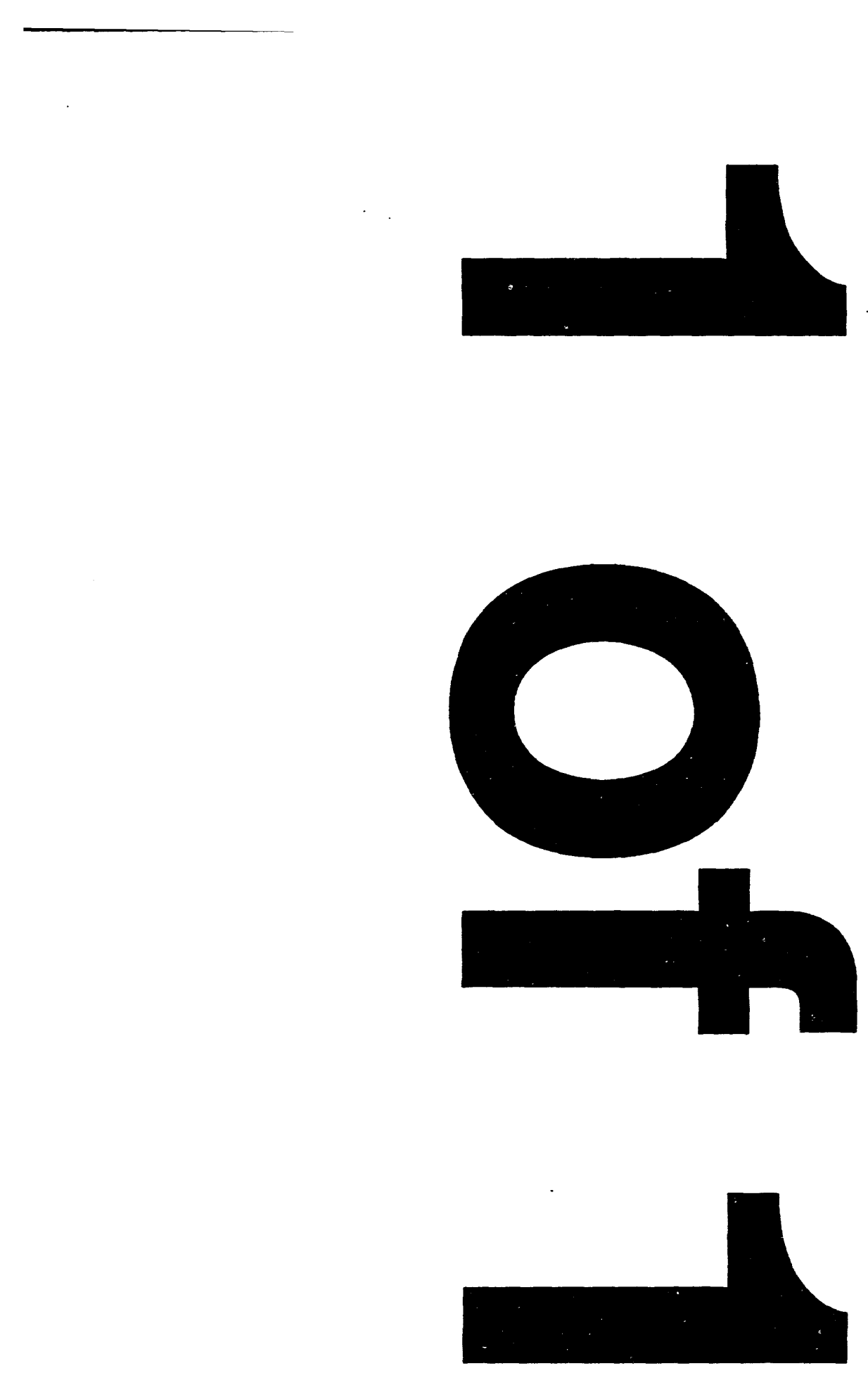
GA-A21412

\title{
PERFORMANCE \\ CHARACTERISTICS OF THE DIII-D \\ ADVANCED DIVERTOR CRYOPUMP
}

\author{
by \\ M.M. MENON, ${ }^{*}$ C.B. BAXI, G.L. CAMPBELL, \\ K.L. HOLTROP, A.W. HYATT, G.J. LAUGHON, \\ R. MAINGI,* C.C. MAKARIOU, M.A. MAHDAVI, E.E. REIS, \\ M.J. SCHAFFER, K.M. SCHAUBEL, J.T. SCOVILLE, \\ J.P. SMITH, R.D. STAMBAUGH, and M.R. WADE*
}

This is a preprint of a paper to be presented at the 15th IEEE/NPSS Symposium on Fusion Engineering, October 11-15, 1993, in Hyannis, Massachusetts, and to be printed in the Proceedings.

Work supported by

U.S. Department of Energy

Contract Nos. DE-AC03-89ER51114 and DE-AC05-840R21400

*Oak Ridge National Laboratory.

GENERAL ATOMICS PROJECT 3466

OCTOBER 1993
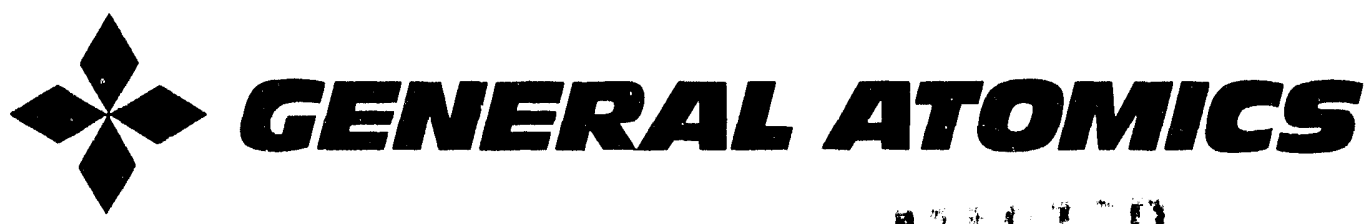

$0+2$

Whon 


\title{
PERFORMANCE CHARACTERISTICS OF THE DIII-D ADVANCED DIVERTOR CRYOPUMP*
}

\author{
M.M. Menon, R. Maingl, and M.R. Wade \\ Oak Ridge National Laboratory \\ P.O. Box 2008, Oak Ridge, Tennessee $37831-8072$
}

\author{
C.B. Baxi, G.L. Campbell, K.L. Holtrop, A.W. Hyatt, G.J. Laughon, C.C. Makariou, \\ M.A. Mahdavi, E.E. Reis, M.J. Schaffer, K.M. Schaubel, J.T. Scoville, J.P. Smith, and R.D. Stambaugh \\ General Atomics \\ P.O. Box 85608, San Diego, California 92186-9784
}

\begin{abstract}
A cryocondensation pump, cooled by forced flow of two-phase helium, has been installed for particle exhaust from the divertor region of the DIII-D tokamak. The Inconel pumping surface is of coaxial geometry, $25.4 \mathrm{~mm}$ in outer diameter and $11.65 \mathrm{~m}$ in length. Because of the tokamak environment, the pump is designed to perform under relatively high pulsed heat loads $\left(300 \mathrm{Wm}^{-2}\right)$. Results of measurements made on the pumping characteristics for $\mathrm{D}_{2}, \mathrm{H}_{2}$, and $\mathrm{Ar}$ are discussed.
\end{abstract}

\section{INTRODUCTION}

The design considerations of a cryocondensation pump for particle exhaust in the advanced divertor configuration of the DIII-D tokamak are described elsewhere [1-3]. In this design, a liquid helium-cooled loop, located under the baffle chamber, serves as the cryopumping surface. In the original plan [1], the cryopumping loop was electrically open to avoid current flow through the loop by induction during plasma current ramps and during disruptions, since any such current will introduce significant heat loading as well as electromagnetic force on the pump. However, subsequent analysis [4] revealed that, in such an open loop configuration, potential differences of up to $300 \mathrm{~V}$ can develop between the electrically isolated cryopump and the DIII-D vacuum vessel during major disruptions and vertical instabilities of high current plasmas. To minimize the probability of arcing between the cryopump and its surroundings under these conditions, a closed loop pump design was selected. This change in configuration introduced two new design challenges: 1) increased heat loading to the He due to currents induced in the loop during plasma current start-ups, and, 2) increased electromechanical forces that would result during plasma disruptions.

The issue of increased heat loading on the pump was investigated experimentally [5]. These experiments revealed that, at a power loading of about $100 \mathrm{~W}$ (representative of power levels anticipated during DIII-D plasma start-up), the temperature on the surface of a $25.4 \mathrm{~mm}$ diam Inconel tube of $10 \mathrm{~m}$ length, cooled by liquid He flowing at a mass flow rate of about $5 \mathrm{~g} / \mathrm{s}$, rises from $4.2 \mathrm{~K}$ to about $8 \mathrm{~K}$. Based on vapor pressure data, a temperature rise above $6 \mathrm{~K}$ will cause deterioration in cryopumping of $\mathrm{D}_{2}$ gas. For $\mathrm{H}_{2}$, the pumping speed will begin to deteriorate at $4.5 \mathrm{~K}$. Further experiments showed that increasing the flow velocity by inserting a thin walled flexible porous coaxial insert in the He line enabled the line to absorb considerably more power (up to $300 \mathrm{~W}$ ) while maintaining the temperature rise to less than $0.5 \mathrm{~K}$. This latter scheme was adopted for the closed loop version of the pump. The mechanical stability of this new configuration was analyzed extensively and a spring loaded pump support scheme was designed, that minimizes displacement of the pump during plasma disruptions while permitting thermal contraction during cooldown [6].

\section{CALCULATED PUMPING SPEED OF THE CRYOPUMP}

Fig. 1 shows the pumping configuration as installed in the DIII-D tokamak. A pumping speed of $50,000 \mathrm{l} / \mathrm{s}$ was estimated [1] for $\mathrm{D}_{2}$ at $0.5 \mathrm{mT}$ Torr using a Monte Carlo code, DEGAS. This calculation assumed the pumping surface, the liquid nitrogen shield, and the secondary shield to be toroidally continuous. Mechanical design of the pump is described elsewhere [3]. The cryo-condensation pumping surface is made of $0.89 \mathrm{~mm}$ wall Inconel tube of $25.4 \mathrm{~mm}$ diameter and $11.68 \mathrm{~m}$ length, cooled by forced flow of two-phase helium flowing at a rate of $5 \mathrm{~g} / \mathrm{s}$. Because of the need to withstand high mechanical loads, a large number of low heat leak spring supports are used between the He line and the surrounding liquid nitrogen-cooled line (one every $15^{\circ}$ ). Since each spring support has an axial length of $7.5 \mathrm{~cm}$, the pumping area masked by the springs is about $18 \%$ of the total surface area. Further, the numerical calculations assumed a toroidally continuous opening through which the particles reach the pump, while structural considerations required the openings on the secondary shield and the inner radiation shield to be in the form of discrete slits. Also, about $10 \%$ of the pumping surface is masked off to prevent interference with certain diagnostics. The mechanical supports to the pump (24 in number) also reduced the conductance to the pump. An approximate estimate for the loss in pumping speed, from the combined effect of the geometrical factors described above, is about $30 \%$. With this correction, the calculated value for the pumping speed for $D_{2}$ is about $35,000 \mathrm{l} / \mathrm{s}$.

\section{MEASURED CHARACTERISTICS OF THE CRYOPUMP}

\section{A. Cooldown and Regeneration Features}

The cryogenic system is a closed loop system, with cryostat located near the tokamak $[7,8]$. The cryostat can be

*Manuscript received October 11, 1993. This work was supported by the U.S. Department of Energy under Contract No. DE-AC03-89ER51114 with General Atomics and DE-AC05-84OR21400 with Martin Marietta Energy Systems, Inc. 

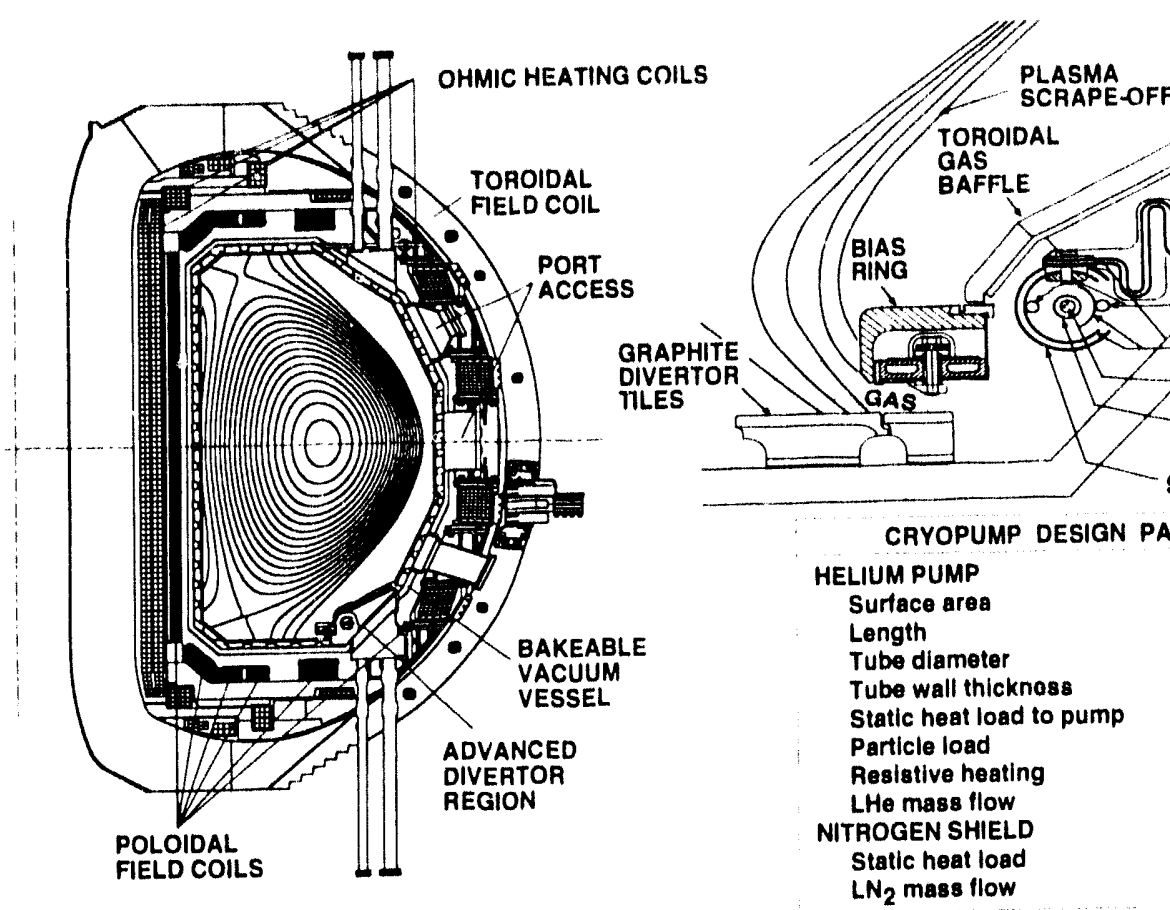

Fig. 1. Cross section of the DIII-D tokamak (left) and the cross section of the advanced diventor components including the pump (right).

independently cooled by bypassing the pump. Starting from a cold cryostat, cooldown of the pump from room temperature takes approximately an hour. In the DIII-D tokamak. He glow discharge wall conditioning is routinely applied after each plasma discharge. To initiate the glow requires a He pressure surge of about $50 \mathrm{mT}$ Torr. Once the glow discharge strikes, the He gas flow is reduced and the pressure is maintained at about 2 mTorr. The liquid He flow is cut off just before the glow discharge cleaning is initiated. The He gas pressure surge during the glow initiation period regenerates all the $D_{2}$ frost on the cryopump. During the discharge cleaning, which typically lasts about 5 minutes, the liquid He flow is valved off and, by the end of the 5 minute glow, the cryopump outlet temperature warms up to about $30 \mathrm{~K}$. The liquid nitrogen flow is continuously maintained. Cooldown at the end of the glow is accomplished by reopening the liquid He flow control valve. During a typical cycle with 5 minutes of glow, liquid He flow is reestablished in less than three minutes after opening the flow control valve. In this mode of operation, a fresh pumping surface is maintained at the beginning of each plasma discharge, without compromising the discharge duty cycle, and accumulation of $D_{2}$ frost to explosive levels from prolonged plasma operation is eliminated.

\section{B. Pumping Speed}

Two capacitance manometers, one located in the main torus and the other in the baffle chamber, were used to measure the pressure. Controlled amounts of gas were introduced using feedback controlled piezo electric valves. These flow control valves were calibrated by measuring the pressure rise after puffing a pulse of gas of known duration into the tokamak of known volume $(35,0001)$, isolated from all pumps. Denoting the gas flow rate by $Q$ (Torr $1 / \mathrm{s}$ ), the pumping speed by $S_{p}(1 / s)$, the conductance between the torus and the baffle chamber hy $C_{h}(1 / s)$, the torus pressure by $p_{t}$ (Torr), and the baffle pressure by $\mathrm{p}_{b}$ (Torr),

$$
Q=C_{b}\left(p_{t}-p_{b}\right)=S_{p} \times p_{b}
$$

These measurements were checked by determining the decay rate of pressure after abruptly cutting off the gas flow, since the effective pumping speed is given by:

$$
S_{e f f}=\left(S_{p} \times C_{b}\right) /\left(S_{p}+C_{b}\right)=V / \tau
$$

where $V$ is the tokamak volume and $\tau$ is the e-folding time for the torus pressure decay.

The pumping speed is a function of gas species, pressure, and the temperature of the pumping surface. Although the temperature of the coolant is constant, the temperature of the pumping surface can be affected by the power flux incident on the pump. For $\mathrm{H}_{2}$ gas, because of its relatively high vapor pressure near the boiling point of $\mathrm{He}$, a small increase in the surface temperature can cause a significant decrease in pumping speed. The pumping speed was measured for three different gases, $\mathrm{H}_{2}, \mathrm{D}_{2}$, and $\mathrm{Ar}$. Measurements were done in a wide range of pressure, but the primary interest was in the millitorr range, since the pressure measured under the baffle chamber during diverted plasmas are typically in the millitorr range. The results of pumping speed measurements for $D_{2}$ are shown in Fig. 2. The apparent pumping speed increased with increase in pressure in the entire range studied. The data at the low pressure end has a higher margin of error since the capacitance manometers are not accurate at very low pressures. At pressures in the millitorr range, the mean free path is comparable with the entrance aperture dimensions of the cryopump, and therefore, the flow regime is in transition from molecular to the viscous. In this transition regime the conductance to the pump is proportional to the pressure, which 
explains the results shown in Fig. 2. The geometry of the pump and its surroundings is not easily amenable for a quantitative estimate of the effect of pressure on conductance. but an approximate linear dependence of conductance on pressure is observed in simpler geometries.

The pumping speeds measured for hydrogen at different pressures are shown in Fig. 3. The pumping speeds for $\mathrm{H}_{2}$ and $\mathrm{D}_{2}$ dot not agree with the theoretically expected $\mathrm{M}^{-1} .5^{2}$ relationship, $M$ being the atomic mass number. The correction factor arising from the molecular to viscous transition regime depends on the mean-frec-path, which is inversely proportional to the square of molecular diameter. Also, at the operating temperature of $4.35 \mathrm{~K}$ (the boiling point of He corrected for the $33 \mathrm{kbar}$ ), the sticking coefficient for hydrogen may be less than unity. If the conductance effects are ignored, the measurements suggest a sticking coefficient of about 0.8 at 4.35 K. The pumping speed was also measured for Ar gas, in the pressure range of 1-2 mTorr (see Table I). However, because of the lower pumping speed and consequently higher time constant for the pressure rise for Ar, equilibrium pressures could not be reached during the $9 \mathrm{~s}$ gas pulse. The pumping speed for Ar was estimated by using the measured conductance and the decay rate of the pressure trace. These measurements were also checked by extrapolating the measured baffle pressures to obtain the equilibrium values $\left[\mathrm{P}_{\mathrm{b}}(\infty)\right]$ using the expression:

$$
P_{b}(t)=P_{b}(\infty)[1-\exp (-S \times t V)]
$$

As indicated before, power is dissipated in the pump during plasma current ramp-up since the cryopump forms a closed loop. The maximum estimated power is about $80 \mathrm{~W}$, lasting for about $1.5 \mathrm{~s}$. Power is also incident on the pump in the form of energetic particles reflected off the diverted plasma strike region. The estimated contribution from the energetic particles and radiation is about $20 \mathrm{~W}$, but because of the uncertainty on the reflection coefficients in the energy range of interest, there is considerable uncertainty on this figure. Experiments with prototypical geometry suggested a safety margin of about 3 for the allowed heat loading on the pump, but these experiments also revealed that the temperature increases on the pumping loop is strongly affected by the details of the flow loop configuration. Therefore, the power handling ability in the actual configuration of the pump was

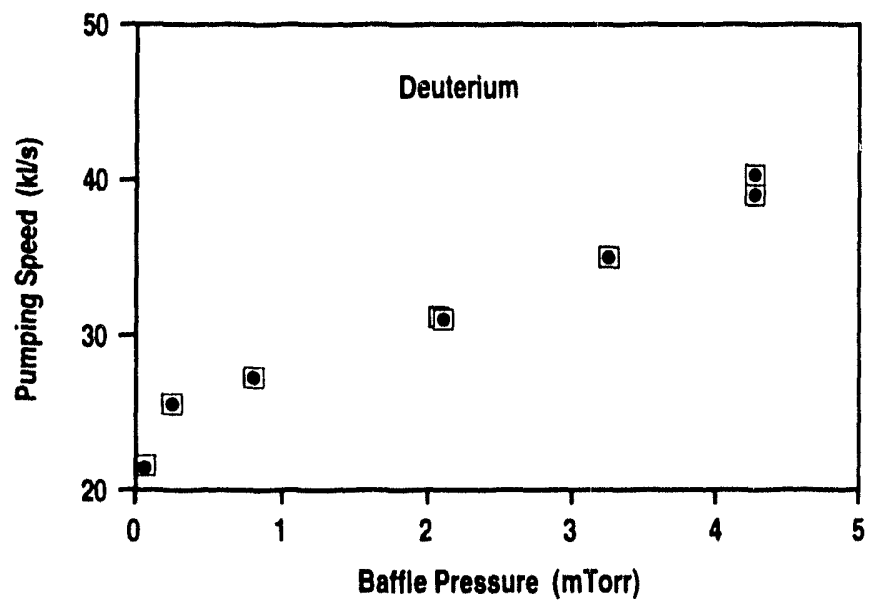

Fig. 2. Pumping speed versus pressure in $D_{2}$.

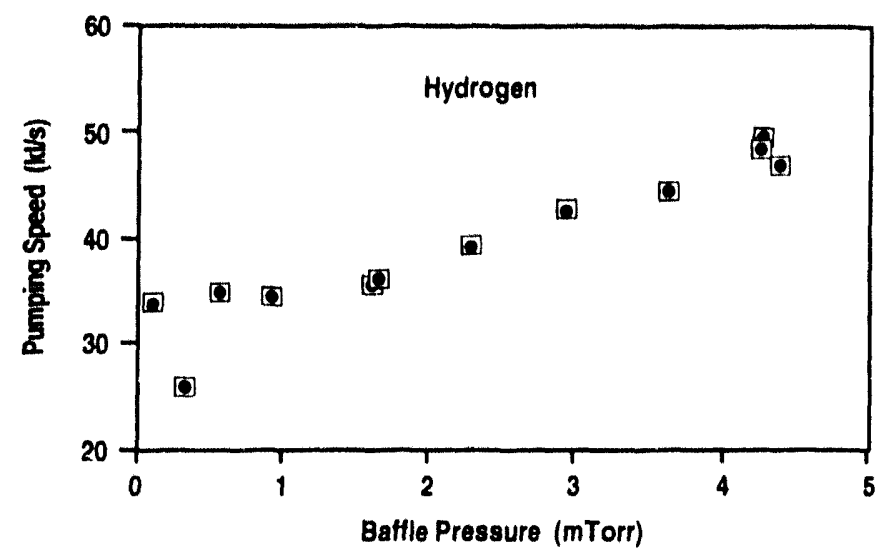

Fig. 3. Pumping speed versus pressure in $\mathrm{H}_{2}$.

Table I

Pumping Speed for Argon

\begin{tabular}{ccc}
\hline $\begin{array}{c}\text { Baffle } \\
\text { Pressure } \\
(\mathrm{mT} \text { Torr })\end{array}$ & $\begin{array}{c}\text { Pumping Speed } \\
\text { [Using Eq. (1)] } \\
(\mathrm{l} / \mathrm{s})\end{array}$ & $\begin{array}{c}\text { Pumping Speed } \\
\text { [Using Eq. (3)] } \\
(\mathrm{l} / \mathrm{s})\end{array}$ \\
\hline 1.19 & 8240 & 8190 \\
2.02 & 8170 & 8140 \\
2.37 & 8470 & 9560 \\
2.42 & 8350 & 9530 \\
\hline
\end{tabular}

determined experimentally by inducing a current in the pumping loop by means of the tokamak ohmic heating coil. Because of maximum current limitations of the ohmic heating supply for long pulse duration (10 s), a triangular current waveform was used to excite the coil to induce a square wave voltage on the cryopump loop. The magnitude of the induced voltage is decided by the slope of the current waveform. The period of the induced waveform was selected to minimize the shielding effect of the torus. Numerical calculations suggested a frequency of $3 \mathrm{~Hz}$. The current, voltage and power waveforms for a pulse of $100 \mathrm{~W}$ are shown in Fig. 4. The experiment was done using $\mathrm{D}_{2}$, the gas commonly used to fuel DIII-D plasmas. Fig. 5 shows that there was no noticeable effect with application of power on pumping speed for $D_{2}$, for power levels up to $330 \mathrm{~W}$ (the maximum value tested). This experiment demonstrated that the pumping speed in deuterium will not be affected by plasma operations.

\section{Exhaust Throughput}

The maximum operating pressure is dependent on the pulse duration. At a mass flow rate of $5 \mathrm{~g} / \mathrm{s}$, a pulse duration greater than $50 \mathrm{~s}$ may be regarded as steady state since the time taken by the helium coolant to travel the entire length of the pump is about $50 \mathrm{~s}$. Because of limitations on the gas flow system and on the computerized data acquisition system we were unable to use long pulses at high flow rates. However, a pressure of 9 mTorr of $\mathrm{H}_{2}$ for a pulse duration of $7 \mathrm{~s}$ was maintained by the pump, with no indication of any instability. Since the pumping speed for hydrogen at this pressure exceeds $45,000 \mathrm{l} / \mathrm{s}$, the throughput of the pump exceeded 325 Torr $\ell / s$ or about 300 Torr $\cdot 1 / \mathrm{s}^{-1} \cdot \mathrm{m}^{-2}$. 


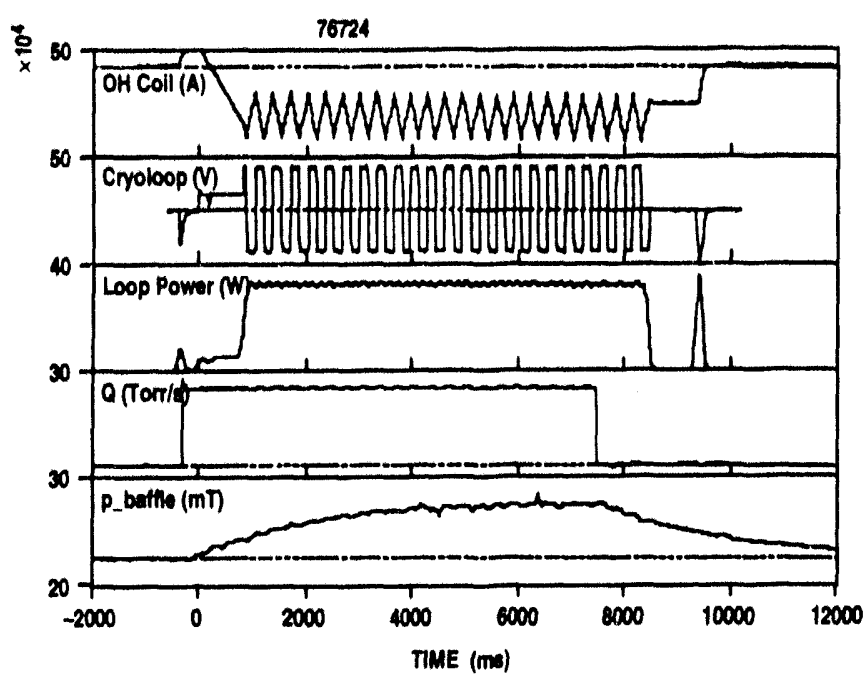

Fig. 4. Traces showing, from top to bottom: 1) ohmic heating coll current, 2) voltage induced in the cryopump loop, 3) power dissipated in the pump, 4) gas throughput into torus, 5) pressure in the baftle chamber.

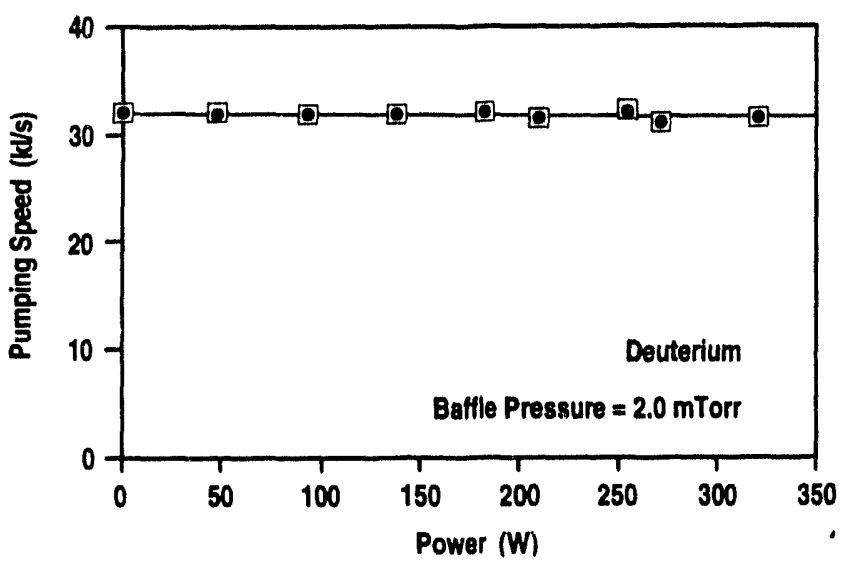

Fig. 5. Effect of power on pumping speed.

Similarly, a pressure of $9 \mathrm{mT}$ Torr of $\mathrm{D}_{2}$ for a pulse duration of 9 swas also successfully handled by the pump. In a separate experimental observation, $11 \mathrm{~m}$ Torr of He pressure was maintained for at least $15 \mathrm{~s}$, but the pump became unstable at some pulse duration (undetermined) that was greater than $15 \mathrm{~s}$.

\section{PARTICLE EXHAUST IN THE DIVERTOR CONFIGURATION}

The pump is located under the baffle (Fig. 1), where the pressure is sensitively affected by the position of the plasma strike region relative to the entrance aperture of the baffle chamber $[9,10]$. By controlling the position of the strike region, the baffle pressure and hence the particle exhaust from the plasma can be carefully controlled. Fig. 6 shows the results obtained for a scan of the divertor X-point during a plasma discharge. A four-fold increase in particle exhaust is seen as the diverted plasma strikes close to the mouth of the baffle chamber. In experiments with heavy gas puffing, a maximum particle exhaust of about 400 Torr $1 / \mathrm{s}$ has already been achieved [11]. This particle exhaust rate is a factor of 20 higher than the initial design goal.

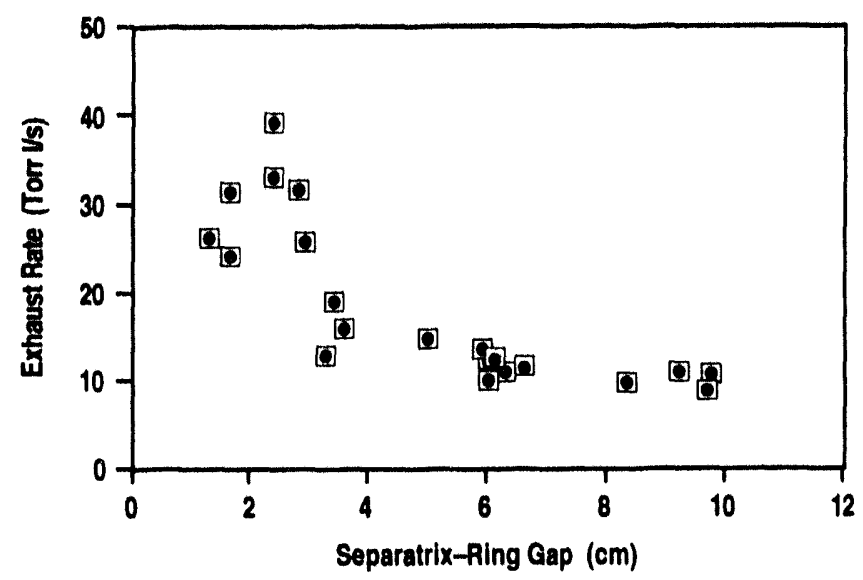

Fig. 6. Exhaust rate versus separatrix-ring gap.

\section{CONCLUSIONS}

A cryocondensation pump for particle exhaust from the lower outside divertor region of the DIII-D tokamak has been installed and operated. The pump provides high pumping speeds $\left(30,000-40,000 \mathrm{l} / \mathrm{s}\right.$ in the $1-4 \mathrm{~m}$ Torr range of $D_{2}$ pressure), in agreement with numerical predictions. Other noteworthy features of the cryopump are: 1) ability to handle high power dissipation (about $350 \mathrm{Wm}^{-2}$ ) without exhibiting any deterioration in $D_{2}$ pumping speed, and, 2) high $D_{2}$ throughput $(>400$ Torr $1 / \mathrm{s}$ ) for pulsed applications.

\section{REFERENCES}

[1] M.M. Menon, P.M. Anderson, C.B. Baxi, A. Langhorn, J.L. Luxon, M.J. Schaffer, et al., "Particle exhaust scheme using an in-vessel cryocondensation pump in the advanced divertor configuration of the DIIl-D tokamak," Fusion Technology, vol. 22, 1992, pp. 356-370.

[2] K.M. Schaubel, C.B. Baxi, G.L. Campbell, G.J. Laughon, M.A. Mahdavi, M.M. Menon, et al., "Development of an in-vessel cryopump system for the DIII-D tokamak," to be published in Advances in Cryogenic Engineering, vol. 39.

[3] J.P. Smith, K.M. Schaubel, C.B. Baxi, G.L. Campbell, A.W. Hyatt, A.L. Langhorn, et al., this conference.

[4] M.J. Schaffer, private communication

[5] G.J. Laughon, private communication

[6] E.E. Reis, I. Almajan, C. Baxi, M.M. Menon, M.J. Schaffer, L. Sevier, et al., "Design and analysis of a cryopump for the DIIl-D advanced divertor," in Proc. 17th Symp. on Fusion Technology, September 14-18, 1992, Rome, Italy.

[7] K.M. Schaubel, C.B. Baxi, et al., "Design of the advanced divertor pump cryogenic system for DIII-D," in Proc. 14th IEEE/NPSS Symposium on Fusion Engineering, San Diego, CA., September 30 through October 3, 1991, vol. 2. pp. 1222-1225.

[8] K. Schaubel, G.J. Laughon, G.L. Campbell, A.R. Langhorn, N.C. Stevens, M.L. Tupper, this conference.

[9] C.C. Klepper, J.T. Hogan, D.N. Hill, R. Maingi, L.W. Owen, D. Buchenauer, et al., "Divertor neutral pressure enhancement," $\mathrm{Nucl}$. Fusion, vol. 33, 1993, pp. 533.

[10] M.A. Mahdavi, M.J. Schaffer, S.L. Allen, P.M. Anderson, M.E. Austin, C.B. Baxi, et al., "Active density control in DIll-D H-mode plasmas," in Proc. 20th European Physical Society Conf. on Controlled Fusion and Plasma Physics, July 26-30, 1993, Lisbon. Portugal.

[11] M.J. Schaffer, N.H. Brooks, J.W. Cuthbertson, S.I. Lippmann, M.A. Mahdavi, R. Maingi, et al., "Scrape-Off layer flow enhancement with divertor pumping on DIII-D," to be presented at the APS/DPP Meeting, St. Louis, November 1-5, 1993. 

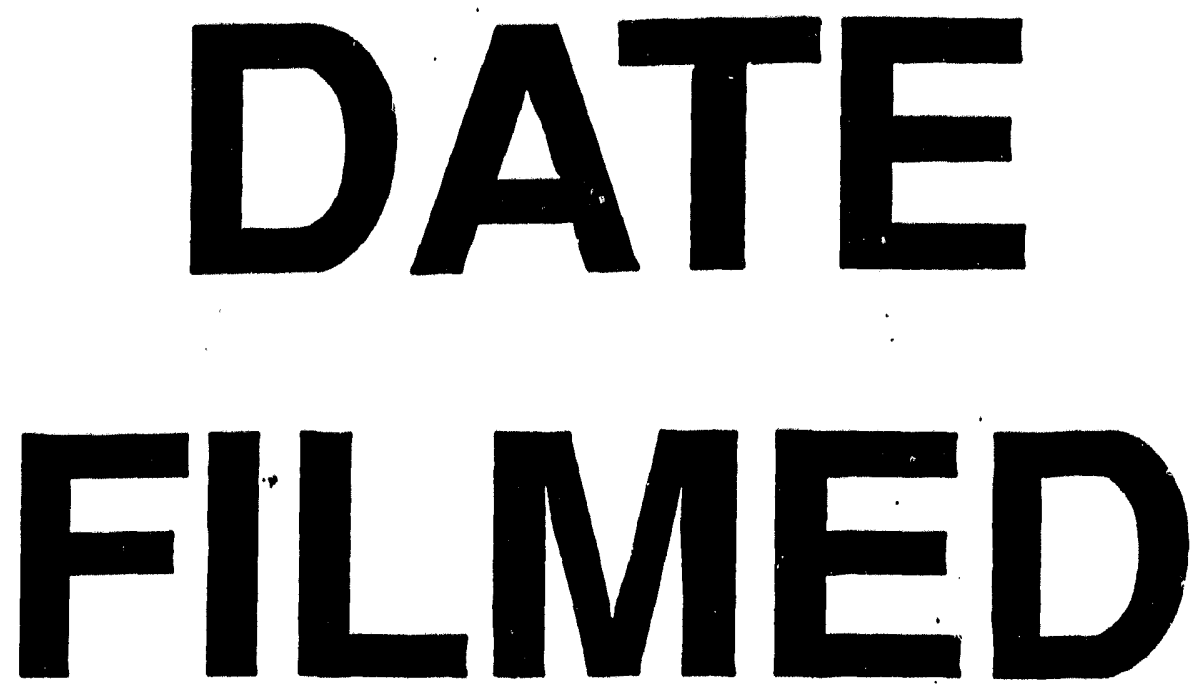

$12 / 27 / 93$
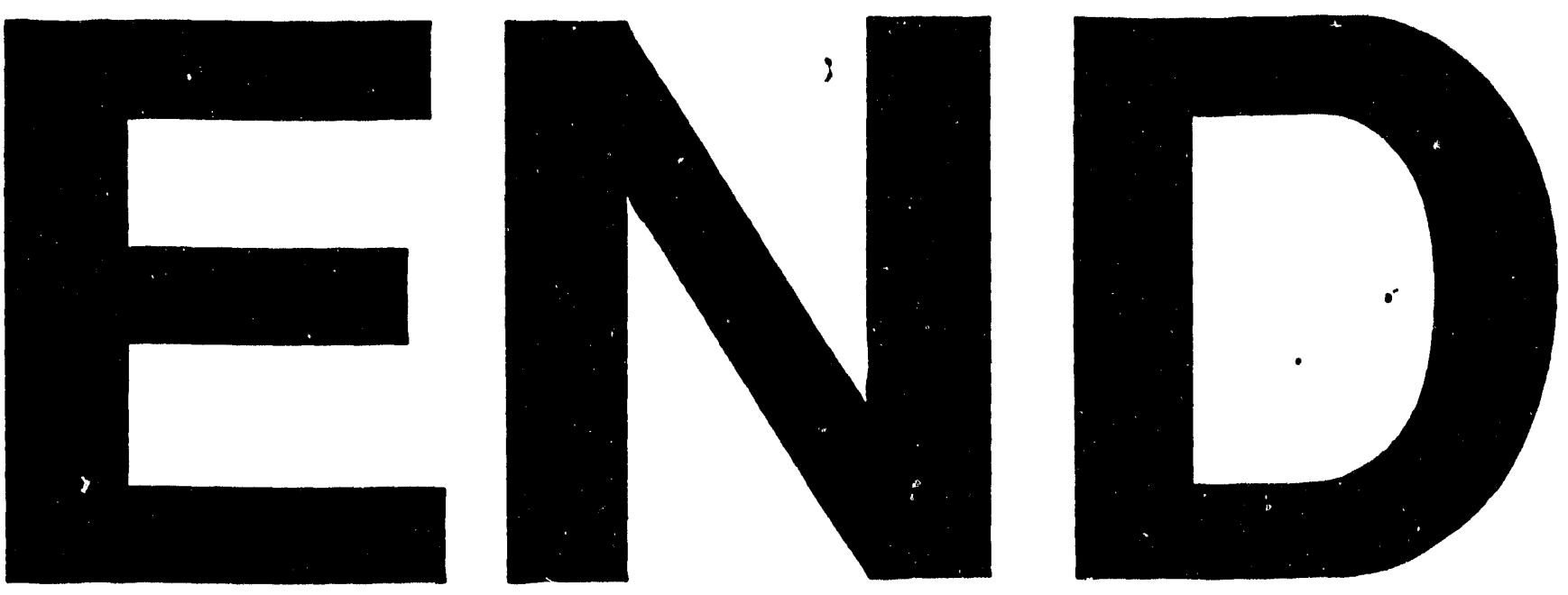


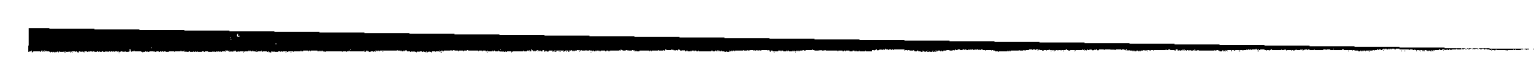

